\title{
Can a machine tickle?
}

\author{
CHRISTINE R. HARRIS and NICHOLAS CHRISTENFELD \\ University of California, San Diego, La Jolla, California
}

\begin{abstract}
It has been observed at least since the time of Aristotle that people cannot tickle themselves, but the reason remains elusive. Two sorts of explanations have been suggested. The interpersonal explanation suggests that tickling is fundamentally interpersonal and thus requires another person as the source of the touch. The reflex explanation suggests that tickle simply requires an element of unpredictability or uncontrollability and is more like a reflex or some other stereotyped motor pattern. To test these explanations, we manipulated the perceived source of tickling. Thirty-five subjects were tickled twice - once by the experimenter, and once, they believed, by an automated machine. The reflex view predicts that our "tickle machine" should be as effective as a person in producing laughter, whereas the interpersonal view predicts significantly attenuated responses. Supporting the reflex view, subjects smiled, laughed, and wiggled just as often in response to the machine as to the experimenter. Self-reports of ticklishness were also virtually identical in the two conditions. Ticklish laughter evidently does not require that the stimulation be attributed to another person, as interpersonal accounts imply.
\end{abstract}

One of the most basic observations about tickling is that one does not laugh and smile when one tries to tickle oneself. The inability to self-tickle is compelling evidence that tickling requires some factor beyond just a particular sort of physical stimulation of the ribs, feet, or other body part. However, the precise nature of the additional factor has been the subject of some debate (Harris, 1999). On one side is a reflex view, suggesting that what is lacking in self-tickle is unpredictability or uncontrollability. On the other side of the debate is the interpersonal view, proponents of which suggest that one cannot tickle oneself because tickling is fundamentally an interpersonal experience.

The notion that the tickle response is a reflex was advocated by G. Stanley Hall and other writers around the turn of the century (Hall \& Allin, 1897; Sully, 1902). A writer for the Edinburgh Review ("Art," 1912) went as far as to claim that "in the phenomenon of tickling we get laughter produced as a purely physiological reflex, so unconnected with mental appreciation" (p. 385). More recently, Black (1984) noted that laughter "is unique in that it is both a reflex and a psychosomatic event. . . . For example, as a reflex, laughter can be elicited by tickling; as a psychosomatic event, it can be elicited by a circus clown dropping his pants" (p. 2995). A similar view was suggested by Francis Bacon (1677), who observed that, when tickled, "men even in a grieved state of mind, yet cannot sometimes forbear laughing" (p. 151). Stearns (1972) and Fridlund and Loftis (1990) have also argued that tickle should be considered a reflex.

We gratefully acknowledge Meg Notman's assistance with the creation of "Mechanical Meg" and her willingness to tickle the feet of strangers. We also thank Benjamin Liu for providing us with several references from antiquity. Address requests for reprints to C. R. Harris, Department of Psychology-0109, University of California, San Diego, La Jolla, CA 92093-0109 (e-mail: charris@psy.ucsd.edu).
If tickle is a reflex (or some other innate stereotyped behavioral response such as a fixed action pattern), why can we not elicit it in ourselves? Several possible mechanisms that are consistent with the reflex notion might be responsible for inhibiting self-tickle. For one, self-tickle may be impossible because the element of surprise is missing. On this view, tickle may be more akin to the startle reflex than to the knee jerk; one can no more startle oneself than tickle oneself. Another account has been suggested by Weiskrantz, Elliot, and Darlington (1971), who argue that to some extent the command, or efferent signal, works to prevent people from tickling themselves. Thus, what is sometimes termed exafference (stimulation uncorrelated with a motor command) may be required in order to elicit the tickle response. While several writers have referred to the tickle response as reflexive, tickle may be more complicated than a standard reflex. It may be more appropriate to view the behavior as a stereotyped motor pattern that requires a particular releasing stimulus. Although the specific mechanisms and terms vary across writers, what unites this approach to tickle is the notion that the inhibition of self-tickle reflects relatively low-level physiological mechanisms. We will return to these complexities in the Discussion section.

In contrast, the interpersonal approach to tickle assumes that we cannot tickle ourselves because the stimulation must be known to come from another person, rather than simply unpredictable or exafferent. For example, KeithSpiegel (1972) wrote that "not just anyone or anything can do the tickling and elicit laughter. It must be administered by a 'friendly' source and done in a playful manner" (p. 18). Koestler (1964) suggested that laughter will occur only if the person being tickled views it as a harmless and playful mock attack. Shultz (1976) aptly points out an important implication of Koestler's suggestion: "The tickling must come from another person; otherwise it could not be interpreted as an attack" (p. 32). Levine 
(1979) describes tickling as "an interaction between two people in which the relationship is familiar and friendly" and notes in tickle a "dependence upon a second person" (p. 48). ${ }^{1}$ Foot and Chapman (1976) propose that "the social ... context in which tickling between two persons occurs is fundamental to the instigation of laughter" (p. 189). The interpersonal view also predates modern psychology: Charles Darwin (1873/1965) argued that the interpersonal nature of the interaction was critical, and he speculated that if a stranger tried to tickle a child, the child would scream with fear rather than squeal with laughter.

While opinions about tickle are common, empirical observations are in short supply. One way to distinguish between the two views of tickle is to examine whether manipulations of the interpersonal context alter the laughter produced by tickling. Leuba (1941), in a study of two of his own children, gathered evidence that bears on this issue. He found that tickle-induced laughter emerged despite his having deliberately refrained from tickling his children during playful situations and having always hidden his face behind a mask so that the infants would not associate tickling with smiles and laughter. Although this evidence supports the reflexive view, it is far from conclusive. Leuba did not have a control group, and it is also possible that the children, even without seeing their father's face or hearing him laugh, stij] viewed his tickling as well-intentioned and friendly.

In the present investigation, we use a more direct manipulation to test one key aspect of the interpersonal nature of tickle-namely, that the belief that another person is doing the tickling is essential in eliciting ticklish laughter. People were tickled twice; once, they believed, by a machine, and once by a human. According to the reflexive view, this should make no difference. If the reason why we cannot tickle ourselves is that the stimulation must be unpredictable or exafferent, the machine should be perfectly capable of tickling. On the other hand, if the reason we cannot tickle ourselves is that tickle is necessarily an interpersonal phenomenon, a machine should be considerably less effective at tickling. Being tickled by a machine, especially if one does not even think that there is another person in the room, is clearly far less of an interpersonal situation than is the event of being tickled by a person.

Most writers who have speculated about tickle have endorsed the interpersonal view which predicts that a machine should not be an effective tickler. The public also appears to share this opinion. Of the 48 undergraduates whom we surveyed, $50 \%$ thought that a tickle machine could not produce laughter, and only $15 \%$ thought it could be as effective as a person who provided the same stimulation.

It should be noted that the sort of tickle that results in laughter may be different from the tickle that results in an "itchy" sensation. The distinction between these sensations was noted as far back as 1892 in the Dictionary of Psychological Medicine. The first type of tickle is elicited by a light touch across the skin of almost any part of the body. Akin to "a moving itch," it creates the desire to rub or scratch the tickled surface. The second type of tickle, usually elicited by a heavier touch to particular areas of the body such as the armpits or ribs, results in squirming and laughter. G. Stanley Hall, writing with Arthur Allin (1897), suggested that the feather-type tickle be called "knismesis" (light tickle), and the laughter-inducing tickle, "gargalesis" (heavy tickle). One can readily elicit knismesis in oneself (this is easily demonstrated by dragging a fingernail lightly over one's skin). However, one cannot produce gargalesis in oneself; the present investigation focuses on this peculiar fact.

\section{METHOD}

\section{Subjects}

Twenty-one female and 14 male undergraduate students enrolled in lower division classes at the University of California, San Diego, participated in exchange for course credit. Their ages ranged from 18 to $28(M=19.9, S D=2.0)$.

\section{Apparatus and Materials}

The tickle machine was designed to look and sound like a robotic hand that was capable of movement without the experimenter's assistance. The hand was attached by a long flexible hose to an impressive array of equipment that could plausibly control its motion. This equipment, when turned on, produced a vibrating sound that could be that of a genuine robotic apparatus.

\section{Procedure}

Subjects reported alone to the "Attention and Perception Laboratory." They were told that they would be tickled twice, once by the experimenter and once by the machine. They were instructed to behave as naturally as possible and were told that they would be asked to rate the intensity of the tickle after each episode. To aid in the deception, the subjects were asked to wear earplugs and a blindfold, supposedly to enable them to attend to the tickle without distraction. The subjects were also instructed to keep their eyes shut throughout the experiment, ostensibly to prevent the blindfold from irritating their eyes. The blindfold and earplugs were not taken off until both tickling episodes had been completed. Nonetheless, the subjects could hear instructions from the experimenter and the noise from the machine. To further aid in the deception, the experimenter also leaned down and held her hand just in front of the subject's foot during the trials in which she was supposedly tickling the subject. When the experimenter was present during the machine tickle trials, she rolled her chair away from the subject so that she would not be within reach of the subject's foot and so that her voice would come from a different direction than the machine's noise. For the triais in which the experimenter left the room, subjects could hear her leaving and the door closing behind her.

Before donning the earplugs and blindfold, the subject was seated with the bare right foot dangling off of a footstool that was placed immediately in front of the tickle machine's hand. The subject's leg was strapped with Velcro to the footstool. Immediately before each tickling episode, the subject was told whether the experimenter or the machine would be performing the tickling. The noise from the machine also made this obvious. The order of the alleged tickler was randomly assigned. In addition, for half of the subjects, the experimenter left the room during the machine tickle trial, ostensibly to watch the experiment through a video monitor in an adjacent room. Before leaving the room, she pushed one of the buttons on the machine and told the subject that the machine tickling would initiate in approximately $7 \mathrm{sec}$ and that the machine would 
Table 1

Mean Ticklishness Ratings as a Function of Tickler

\begin{tabular}{lccccc}
\hline & \multicolumn{2}{c}{ Behavior } & & \multicolumn{2}{c}{ Self-Report } \\
\cline { 2 - 3 } \cline { 5 - 6 } Condition & $M$ & $S D$ & & $M$ & $S D$ \\
\hline Machine & 2.79 & 0.78 & & 4.85 & 1.34 \\
Experimenter & 2.82 & 0.77 & 4.82 & 1.22 \\
\hline
\end{tabular}

Note--The scores for the behavior measure represent means on a 0 - 4 scale, and self-reports are on a 0-7 Likert-type scale. Higher numbers indicate greater ticklishness. Each number is based on 33 subjects.

automatically turn itself off after a preprogrammed amount of time. The machine tickling did not begin until the experimenter was out of the room. Each tickling episode lasted for $5 \mathrm{sec}$.

In order to be sure that any significant effect of experimental condition would not be attributable to a difference in the tactile stimulation itself, neither the machine nor the experimenter actually performed the tickling. Instead, the tickling was performed by a hidden research assistant. Before the subject entered the tickle room, the research assistant hid under a large table, which was covered with a floor-length black table cloth. Other tables in this room also were covered with cloths of varying lengths to minimize suspicion regarding the use of the table cloth. To perform the tickling, the research assistant lifted the table cloth a few inches and reached out to the subject's foot. To ensure that the machine noise and the tickling started simultaneously, the research assistant controlled a switch which powered the machine's sound. ${ }^{2}$

At the end of the experimental session, the subject was carefully questioned regarding any suspicions and knowledge about the experiment. Only 1 subject expressed skepticism about the tickle machine. Another subject thought that the machine had tickled her both times. The data from these 2 subjects were not included in the analyses.

\section{Dependent Measures \\ Two measures of ticklishness were obtained. Immediately after each tickling episode, the subject orally rated the tickle sensation using a Likert-type scale of 0 (not at all ticklish) to 7 (extremely ticklish). Behavioral measures of tickle were coded from videotape, on a five-point scale. Two independent coders scored each tickle episode, with $0=$ no apparent response; $1=$ voiceless smiling; $2=$ laughter; $3=$ twisting or wiggling in response to the tickle; and $4=$ subject pulls limb away from tickler thereby stopping the tickling before the allotted $5 \mathrm{sec}$. This response intensity scale has been used previously and has been shown to correlate highly with duration measures (Harris \& Christenfeld, 1997).}

\section{RESULTS}

It is critical that subjects actually believed that the machine was performing the tickling. The evidence for this comes from two sources. At the end of the experimental session, the subjects filled out a questionnaire describing differences, if any, between the sensation produced by the machine and by the experimenter. The responses clearly show that the subjects did indeed believe that the machine had tickled them. All of the comments from the 35 subjects who answered this question are provided in the Appendix. Following the experiment, the subjects were given a partial debriefing but were not told of the deception. Instead, they were told that we were only describing part of our hypothesis and that a full write-up of the experiment would be available at a later time. The experi- menter telephoned 9 randomly chosen subjects after the study was completed. They were asked about what they had done in the experiment and whether they had any suspicions about any aspect of the experiment. Despite repeated questioning about suspicions, they stated confidently that a machine had tickled them. Not one of the subjects who was called suspected that the tickle machine was not real.

The reliability of the behavioral responses to the tickling was assessed by comparing the scores given by two independent coders. The correlation of ticklishness scores from the two raters averaged across the machine-tickle and experimenter-tickle conditions was $r(31)=.73, p<.0001$, yielding a median Spearman-Brown estimated reliability of .84 for the two-coder composite. Again averaged across the two experimental conditions, the self-report and behavioral dependent variables were significantly associated with each other $[r(31)=.34, p<.05]$.

Because there was no direct or interactive effect of gender on any dependent variable, we collapsed across this dimension for all analyses. To determine whether the belief that a machine was performing the tickling would eliminate tickle responses, we performed two separate paired $t$ tests. The means for behavior and self-reports in the two conditions are presented in Table 1. There was no hint of any difference between tickle responses produced by the experimenter and by the machine for behavior $[t(32)=0.27$, n.s. $]$ or self-report $[t(32)=0.12, \mathrm{n} . \mathrm{s}$. $]$. During the machine-tickle episode, two unpaired $t$ tests revealed no difference in tickle responses when the experimenter was in the room and when the subject believed he/she was alone, for behavior $[t(31)=1.65$, n.s. $]$ and for self-report $[t(31)=0.15$, n.s.]. This lack of differences was not due to a floor effect, because all subjects in all conditions showed at least some behavioral reaction to tickle: Every subject at least smiled or laughed, and many also wiggled and pulled their foot away; selfreport ratings were never lower than 2 on the scale of $0-7$. Our analyses suggest that the belief that a machine or a person is performing the tickling has no effect on how much subjects laugh and smile when tickled or on subjects' self-reports of tickle intensity.

\section{DISCUSSION}

The subjects readily smiled, laughed, and wiggled when tickled by what they believed to be a fully automated mechanical device. These responses were no different from responses to a human tickler and also were not altered when the subjects believed themselves to be entirely alone in the room with the tickle machine. These findings dispute the basic claim of the interpersonal view of tickle-namely, that the inability to tickle oneself reflects the requirement that one believe that another person is responsible for the tickling. Instead, the results are more consistent with the view that the inability to tickle oneself is due to inhibition at some lower physiological level; the tickle-machine works, because it, like another human 
being but unlike oneself, can produce stimulation that is unpredictable and/or not canceled by command or afferent signals.

One might argue that the interpersonal context was not absolutely eliminated in the present work: The person being tickled was being watched during the machine tickle episode, and the tickle machine is a human construction. However, if merely knowing that someone was observing via a video camera were enough to account for the efficacy of the machine, it ought to be possible to selftickle when one is observed by another person. It can be easily demonstrated that this is not so. Thus it is not possible to defend the interpersonal interpretation in this way. Similarly, even if the tickle machine was viewed as a product of human construction, it must represent a severely impoverished interpersonal context in comparison with being tickled by an actual person. We may, in a fit of pique, kick a malfunctioning soda machine, but we do not experience the thoughts and feelings elicited when another person deliberately cheats us; no sane individual would, for example, plot vengeance against the Coke machine. Although it may not be possible to entirely eliminate the social aspects of a situation, it is possible to reduce them dramatically. We did this, and it made no difference in tickle responses.

Even if beliefs about the source of the stimulation are completely irrelevant, tickle might still have evolved to serve functions that arise mostly in interpersonal contexts (see Provine, 1997, for interesting suggestions along these lines). Although our data argue against the most extreme version of an interpersonal view, a looser interpretation of "social context" would still be consistent with the present investigation. For example, Provine argues that any "nonself" entity could be considered social. Unlike the more extreme interpersonal claims regarding tickle, this version of "social" is not inconsistent with the notion that the tickle response is reflexive. The results reported here do not show that the interpersonal context is irrelevant, only that it is not essential.

The present results are generally favorable to the view that the tickle response is some form of innate stereotyped motor behavior, perhaps akin to a reflex. The findings do not reveal precisely what does control the response. Stearns (1972), writing on the physiology of laughter, has argued that tickle is a reflex and has suggested a specific potential reflex arc. Realizing that some might question the use of the term reflex arc for the uncharted and undoubtedly cortical pathways involved in the tickle response, Stearns writes:

use of this term, involving complex pathways in the brain, exceeds the [bounds] of Ramon y Cajal's two neuron reflex arcs or even those of segmental multineuron reflex arcs. It corresponds more to what Globus has called suprasegmental reflex circuits. As Houssay has emphasized: "a simple isolated reflex is a theoretical abstraction," and "the central nervous system normally functions as an integrated unit .... Integration of nervous activity is carried out at different levels of increasing complexity." (p. 57)
Stearns acknowledges that tickle-related behaviors can sometimes be voluntarily inhibited, and suggests this might be due to the afferent and efferent connections between the thalamus and frontal cortex. However, he notes that other reflexes such as the knee jerk or Achilles tendon reflex can also be inhibited.

Although the term reflex has often been favored by physicians writing on tickle, psychologists have tended to shy away from this term. There is controversy about the boundaries between reflexes and other innate speciestypical behavioral dispositions (Shepherd, 1994). In the ethological literature, the terms fixed action pattern (or sometimes modal action pattern; see Barlow, 1996, for discussion) are often used to describe such innate dispositions. ${ }^{3}$ Reflexes are distinguished from fixed action patterns on the basis of their graded character: The more intense the stimulation, the more intense the response. McKimmin (1989) has reported that a high-intensity tickle stimulus produced greater self-reported tickle responses than did a low-intensity stimulus. However, it is not clear whether ticklish laughter shows a graded response to the magnitude of stimulation like that which occurs with the typical reflex, or an all-or-none character like that of a fixed action pattern. This could be a fruitful area for future research. If the concept of a fixed action pattern is appropriate for ticklish laughter, the present results seem to indicate that the releasing stimulus does not have to be another person. Further exploration of the parameters necessary for eliciting ticklish laughter would be interesting. ${ }^{4}$ Our guess is that less is required in order to elicit ticklish laughter than one might have suspected.

Despite two thousand years of speculation on tickle (since Aristotle; see Cooper, 1922), the paucity of actual research makes it difficult to draw unequivocal conclusions about this enigmatic aspect of human behavior. However, there are a few earlier empirical findings that, like the results reported here, are generally counterintuitive and broadly consistent with a reflexive interpretation of tickle. One is the finding of Newman, O'Grady, Ryan, and Hemmes (1993) that when a neutral verbal stimulus is paired with tickling, the stimulus comes to elicit laughter and smiling on its own. Another is the finding that when subjects perceive that they have control over stopping the tickling, their reports of tickle intensity are not decreased (McKimmin, 1989). Still another is the observation that medical doctors can inadvertently produce ticklish laughter in children during physical exams (Freedman, 1989). Although the exam is an interpersonal situation, it is hard to imagine that children view this situation as "a mock attack."

The argument that tickle is a reflex, or some other kind of innate stereotyped motor pattern, does not imply that the tickle response is unaffected by mood or other psychological states. For example, negative emotional states have been found to potentiate the startle reflex, whereas positive emotional states have the opposite effect (Bradley, Lang, \& Cuthbert, 1993). Similarly, some psychological states might facilitate or reduce laughter in response to 
tickling. We have previously shown that exposing people to humorous stimuli does not increase ticklish laughter, and, similarly, tickling people first does not make them laugh more at humorous stimuli (Harris \& Christenfeld, 1997). This suggests that mirth does not heighten responses to tickling and generally supports the separation of humorous interpersonal reactions and ticklish laughter advocated here. However, it is possible that other mood states might affect tickle. For example, DeSanto, Newman, and Hemmes (1997) found that nervousness interacts with habituation to tickle as does perception of pleasantness of tickle. Provine (1997) also suggests that tickle tends to prime itself, with the response rising in intensity over the course of a tickling session, often until it becomes too intense to be enjoyable.

In the present study, we found no differences in ticklishness of male and female subjects, whether they believed they were being tickled by a woman or by a machine. Previous research has also failed to find evidence of gender differences in tickle responses (Claxton, 1975; Harris \& Christenfeld, 1997). Naturally, this does not imply that gender differences could not arise in other contexts. Under some circumstances, it seems, tickle can have erotic overtones for some people. Possible gender differences in tickle would seem an interesting topic for further investigation, especially since strong gender effects have been found in conversational laughter (Provine, 1993).

In summary, much remains to be explored about the role of social and emotional factors in ticklishness. However, the responses to our tickle machine strongly suggest that ticklish laughter itself does not require any belief that another human being is producing the stimulation.

\section{REFERENCES}

BACON, F. (1677). Sylva sylvarum: or A natural history. London: S. G. \& B. Griffin.

BarLow, G. W. (1996). Ethological units of behavior. In L. Houck \& L. Drickamer (Eds.), Foundations of animal behavior: Classic papers with commentaries (pp. 138-153). Chicago: University of Chicago Press.

BLACK, D. W. (1984). Laughter. Journal of the American Medical Association, 252, 2995-2998.

Bradley, M. M., LaNG, P. J., \& Cuthbert, B. N. (1993). Emotion, novelty, and the startle reflex: Habituation in humans. Behavioral Neuroscience, 107, 970-980.

Claxton, G. (1975). Why can't we tickle ourselves? Perceptual \& Motor Skills, 41, 335-338.

COOPER, L. (Trans.) (1922). An Aristotelian theory of comedy with an adaptation of the poetics and a translation of the Tractatus coislinianus. New York: Harcourt, Brace.

DARWIN, C. (1965). The expressions of the emotions in man and animals. Chicago: University of Chicago Press. (Original work published 1873)

DeSanto, V. R., Newman, B., \& Hemmes, N. S. (1997). The effects of perceived aversiveness on habituation to stimulus in human subjects. Poster presented at the 23rd annual meeting of the Association for Behavior Analysis, Chicago.

FoOt, H. C., \& ChapMAN, A. J. (1976). The social responsiveness of young children in humorous situations. In A. J. Chapman \& H. C.
Foot (Eds.), Humour and laughter: Theory, research, and applications (pp. 187-214). London: Wiley.

FreEdman, B. J. (1989). Now it tickles; now it doesn't: Psychogenic variations in the perception of tactile stimuli. British Medical Journal, 299, 250.

Fridlund, A. J., \& LofTis, J. M. (1990). Relations between tickling and humorous laugher: Preliminary support for the Darwin-Hecker hypothesis. Biological Psychology, 30, 141-150.

HALL, G. S., \& ALLIN, A. (1897). The psychology of tickling, laughing, and the comic. American Journal of Psychology, 9, 1-44.

HARRIS, C. R. (1999). The mystery of ticklish laughter. American Scientist, 87, 344-351.

Harris, C. R., \& Christenfeld, N. (1997). Humour, tickle, and the Darwin-Hecker hypothesis. Cognition \& Emotion, 11, 103-110.

KEITH-SPIEGEL, P. (1972). Early conceptions of humor: Varieties and issues. In J. H. Goldstein \& P. E. McGhee (Eds.), The psychology of humor (pp. 4-39). New York: Academic Press.

KOESTLER, A. (1964). The act of creation. London: Hutchinson.

LAUGHTER. (1912). Edinburgh Review, 215, 383-404.

LEVINE, J. (1979). Humor and psychopathology. In C. Izard (Ed.), Emotions in personality and psychopathology (pp. 37-69). New York: Plenum.

LeubA, C. (1941). Tickling and laughter: Two genetic studies. Journal of Genetic Psychology, 58, 201-209.

McKimmin, P. J. (1989). Tickle sensation, pleasure, anxiety and the role of perceived control. Unpublished doctoral dissertation, California School of Professional Psychology, San Diego.

Newman, B., O'Grady, M. A., Ryan, C. S., \& Hemmes, N. S. (1993). Pavlovian conditioning of the tickle response of human subjects: Temporal and delay conditioning. Perceptual \& Motor Skills, 77, 779-785.

Provine, R. R. (1993). Laughter punctuates speech: Linguistic, social, and gender contexts of laugher. Ethology, 95, 291-298.

Provine, R. R. (1996). Laughter. American Scientist, 84, 38-45.

Provine, R. R. (1997). Yawns, laughs, smiles, tickles, and talking: Naturalistic and laboratory studies of facial action and social communication. In J. A. Russell \& J. M Fernandez-Dols (Eds.), The psychology of facial expression (pp. 158-175). Cambridge: Cambridge University Press.

SHEPHERD, G. M. (1994). Neurobiology (3rd ed.). Oxford: Oxford University Press.

Shultz, T. R. (1976). A cognitive-developmental analysis of humour. In A. J. Chapman \& H. C. Foot (Eds.), Humour and laughter: Theory, research, and applications (pp. 12-36). London: Wiley.

StEarns, F. R. (1972). Laughing. Springfield, IL: C. C. Thomas.

SulLY, J. (1902). An essay on laughter. New York: Longmans, Green. Weiskrantz, L., Elliot, J., \& Darlington, C. (1971). Preliminary observations on tickling oneself. Nature, 230, 598-599.

\section{NOTES}

1. Levine also raises the possibility that tickle is a reflex but notes the inability to tickle oneself as contrary to such a view. However, he may not have been considering the possibility of tactile stimulation administered by a machine.

2. The tickler was not blind to condition. This would have been of concern if the two conditions had been significantly different from one another because of the potential for experimenter expectancy effects. However, since a purported machine was as capable as an experimenter in producing laughter and smiling in subjects, this would not appear to pose any substantial threat to internal validity.

3. In some literature, particularly involving humans, fixed action pattern is sometimes replaced with terms such as species-characteristic or speciestypical stereotyped motor pattern requiring a particular releasing stimulus.

4. Another peculiar species-typical behavior - contagious yawning-has been subjected to this type of analysis, examining, for example, whether an open mouth by itself is a sufficient triggering stimulus (Provine, 1996). 


\section{APPENDIX \\ Subjects' Descriptions of Machine Versus Human Tickling}

Below are given subjects' verbatim written replies to the following question and statement:

Was the sensation produced by the experimenter different than the sensation produced by the machine?

If yes, describe in detail how they were different.

The machine tickled me a lot faster which made me more ticklish

Very slightly-the experimenter's hand was softer

The machine applied more pressure than the experimenter and could not be as accurate (?) or precise as the experimenter. The machine could not accurately reproduce the brushing sensation of the experimenter. Also, since I was already tickled once, perhaps being tickled again in the same place lessened the intensity of the machine's tickle.

Not much-machine was rougher, feel that is.

The experimenter seemed to press hard and light and it changed the sensation, the machine seemed more uniform

They were very much different. The machine felt more repetitious tickling the exact same spot over again, with the same amount of pressure, and speed. The experimenter varied in all this things. More of a spontaneous act. Also different because she had nails and the machine didn't so it was sort of a scrapy feeling.

Texture machine faster and more ticklish

It felt the same to me-like they were both the same sensation

I felt a little less ticklish by the experimenter than by the machine but this seemed to be because I had already been tickled once and knew what to expect.

Machine felt unnatural, temperature different. like walking across plush carpet. speed the same

The machine did it harder and quicker. Probably, it wasn't harder but because of its pointy fingers it was perceived as harder. Most likely the sensation would be different because in my mind I had already distinguished it between the two prior to the experiment. I don't know why I did it. I guess by anticipating its difference, I consequently felt the difference.

The tickle from the machine felt more impersonal. Kind of creepy. It still tickled my foot, but I think the tickle from the experimenter was different because I knew she was trying to elicit a response whereas the machine was merely programmed to perform the action. Although the machine felt almost like real hand, it was still different.

The machine tickled me in the same way the entire time so I continued to be ticklish during that time period. The exp. @ first it was ticklish but all of a sudden she tickled me differently and it was barely ticklish

The experimenter was much more intense. It was much more ticklish than the machine.

Machine was more random and covered more parts of feet-more ticklish.

A little but not much. The tickling by the experimenter seemed quicker and sharper

Not much. in fact I was anticipating that they would be more different than they were.

It was similar, but slightly more ticklish

Almost the same - machine a little more powerful

About the same

Not really they were very similar

The machine was more like a massage. Of course, it was less human, but the lack of skin and flesh didn't make the tickle that effective.

Not by much

It tickled more.

The experimenter was less ticklish than the machine. I didn't feel my muscles twitch as much. Machine seemed to use more pressure. 
APPENDIX (Continued)

The experimenter was more extreme. The experimenter's sensation last longer. After a while, the machine isn't ticklish.

No $\{$ difference $\}$

Only slightly-The machine gave consistent strokes while the experimenter's were a bit more variant.

Yes but not much. Machine was more random and faster. You could tell that the machine was not a person and could not adjust to tickle you in the right spot once found. Overall both felt very similar. The machine was just faster and covered more of the foot.

It was less rapid and elusive

The sensation produced by the experimenter felt "human". It gave more of a ticklish sensation than the machine.

It didn't seem as ticklish. The machine seemed to be more stimulating. Also, since you didn't know when it would stop, the sensation seemed worse. You knew about how long the experimenter was going to tickle you so it wasn't so bad.

(Manuscript received August 5, 1998;

revision accepted for publication December 18, 1998.) 